\title{
THE USE OF SMALL GROUP DISCUSSION STRATEGY IN TEACHING WRITING
}

\author{
Salmon J Hukom \\ sjhukom@yahoo.com \\ FKIP Universitas Pattimura - Ambon
}

\begin{abstract}
The problems always occur in teaching and learning English as a foreign language, and these depend on teachers and students as the center of that process. The teachers have to use appropriate strategy in order to engage the students to achieve their aims of learning.In teaching writing, the teachers always use conventional way such as give the topic and ask the students to write and collect it. There is not any feedback from teachers to students' work. Small group discussion plays important role since it helps the students to help one another to produce good quality of writing product. It also helps the students to have confidence, and the students will get sense of social values in their life.
\end{abstract}

Key words: Cooperative Learning, Small Group Discussion, Teaching Writing

\section{Introduction}

Besides Bahasa Indonesia as an official language that is taught at school, English has a special positton at schools as a foreign language because of its function as a lingua franca for all aspects of international business. Diaz-Rico (2008) states that the world today stands on the brink of an opportunity never before available : the use of a world language, English, that can sustain intercultural contact between individuals who would otherwise have no mutual means of communication. However, the role of English entails a host of social, economic, and political issues.

As a foreign language the Indonesian teachers have faced problems on how to teach this language to the students. The problems is not only on the differences between English and Bahasa Indonesia as a first language like vocabularies, grammar and structure but also the condition of the students. It means that when the students finish studying English at school they come home and do not have partners to practice English. Therefore, teachers' role is very important in during teaching and learning activities. This is accordance with Diaz-Rico's (2008) statement. She states that teachers influence the daily lives of students in their classrooms. They can create a climate of warmth, acceptance, and high achievement for English Iearners.

To produce a good piece of writing, foreign students always face with the difference aspects of their mother tongue like different aspect in Bahasa and English and they can cause problems in producing ideas. Actually, those problems appear like students are difficult to arrange words into sentences, sentences into paragraphs, and so on. Beside that the 
students should consider word choice, the use of appropriate grammar like subject-verb agreement, tense, and the use of articles), the mechanics (e.g. puntuation, spelling), and the organization of ideas into a coherent form.

In traditional classroom, the teacher asks the students to write by giving a topic, then collects the worksheets, grades them, and passes them back to the students.

Dealing with this condition, the teacher should motivate the students to be active in writing. It is better for teacher to manage time wisely by giving opportunity sometime for students to work together or collaborate with their mates and their teacher to produce good quality of a piece of writing in class. Moreover, writing class ideally should be excited activities.

There are many ways in teaching writing, and one of them is Cooperative Learning strategy. This strategy is expected to overcome boredom in writing activities in classroom because it involves all ellements in classroom activities. Both the teacher and the students can interac among others, the students also can work together and the teacher can guide them in process writing activities. According to Larsen-Freeman (2010), cooperative learning essentially involves students learning from each in groups. But it is not the group configuration that makes cooperative learning distinctive; it is the way that students and teachers work together that they can work together more effectivelly.

Furthermore Larsen-Freemen (2010) mentions some principles of cooperative learning:

1. Students are encouraged to think in terms of 'positive interdependence,' which means that the students are not thinking competitively and individualistically, but rather cooperatively and in terms of the group.

2. In cooperative learning, students often stay together in the same groups for a period of time so they can learn how to work better together. The teacher usually assigns students to the groups so that the groups are mixed-males and females, different ethnic groups, different proficiency levels, etc. This allows students to learn from each other and also gives them practice in how to get along with people different from themselves.

3. Social skill such as acknowledge another's contribution, asking other to contribute, and keeping the conversation calm need to be explicity taught.

4. Language acquisition is facilitated by students interacting in the target language.

5. Responsible and accountability for each other's learning is shared.

6. Teachers not only teach language; they teach cooperation as well. Of course, since social skills involve the use of language, cooperative learning teaches language for both academic and social purposes.

There are many kinds of cooperative learning, one of them is small group discussion. Small group discussion is good since it promotes students to work in group, helps one another in giving contribution. 


\section{Nature of writing in school}

Besides students as the center of teaching and learning, the teachers also play important role for the achievement of students. The teachers always preapare various kinds of wrting activities in class. According to O'Malley and Pierce (1996), teacher judgment has always played an important role in the assessment of writing. Teachers ask students to write on any number of topic and then assess the substantive information contained in the message, the clarity of the message conveyed, and the mechanics of writing ( spelling, capitalization, and punctuation ). Teachers typically define the topics for writing, establish the criteria for evaluating the writing, and grade the writing themselves. This teacher-centered approach is not surprising given that many teachers have origins in a transmission model of learning and instruction, in which teacher provide the basic knowledge to be imparted to students. The transmission models isolates content areas in teaching and emphasize mastery of component skiils in sequential order. One byproduct of this model has been that students have learned to write in isolation from reading and other activities related to literacy. Another by-product has been that teachers have tended to over-emphasize mechanics ( spelling, capitalization, and punctuation ) and grammar in their evaluations at the expense of content and meaning in writing.

\section{Purpose and Types of Writing}

Students write to accomplish a variety of purposes and use a number of different genres to do so. Purposes in writing determines the nature of the writing. Students need clear specification of the purposes in order to plan and compose a piece that responds to the task. Writers who gain control over various genres have a broader repertoire of writing abilities and an increased understanding of the value of writing for interpersonal communications, for documenting important ideas, and for achieving their own ends than those who do not.

For what purposes can students be asks to write? There are at least three purposes in writing: informative writing, expressive / narrative writing, and persuasive writing. O'Malley and Pierce (1996) explain the following purposes of writing.

Writers use expository or information writing to share knowledge and give information,directions, or ideas. Examples of informative writing include describing event for experience, analyzing concepts, speculating on causes and effect, and developing new ideas or relationships. This type of writing could include a biography about a well known person or someone from the writer 's life. The writer can rely on existing knowledge or new sources of onformation and can over a range of thinking skiils from simple recall to analysis and synthesis. Informative writing helps writers integrate new ideas and examine existing knowledge.

Expressive / narrative writing is a personal or imaginative expression in which the writer produces stories or essay. This type of writing is often based on observations of people, objects, and places and may include creative speculations and interpretations. It may include an autobiographical incident or a reflections in 
which a writer describes an occurrence in her or his own life. This type of writing is often used for entertainment, pleasure, discovery or, simply, as " fun " writing and can include poems and shorts plays.

In persuasive writing, writers attempt to influence others and initiate action or change. This type of writing is often based on background information, facts, and axamples the writer uses to support the view expressed. Writers use higher-level cognitive skiils in this type of writing, such as analysis and evaluation, to argue a particular point of view in a convincing way. This type of writing might include evaluation of a book, a movie, a consumer product, or a controversial issue or problem. Writers can also use personal experience or emotional appeals to argue in support of their view. The three purposes of writing described here can overlap, as when students write an informative, persuasive essay.

The three purposes of writing describe the kinds of writing students do in second language classroom as well as in grade-level classrooms. ELL students, for examples, write expressive narratives describing personal experiences and write to inform using biographies of people they have known. Many teachers also ask ELL students to write they analyze a point of view or a book they have read.

\section{Cooperative Learning}

The term cooperative learning refers to students working in teams on anassignment or project under conditions including the team members who work individually to complete the content of the assignment.

\section{What is Cooperative Learning}

According to the Johnson \& Johnson model (1991) cooperative learning is instruction that involves students working in teams toaccomplish a common goal, under conditions that include the following elements:

1. Positive interdependence. Team members are obliged to rely on one another to achieve the goal.If any team members fail to do their part, everyone suffers consequences.

2. Individual accountability. All students in a group are held accountable for doing their share ofthe work and for mastery of all of the material to be learned.

3. Face-to-face promotive interaction. Although some of the group work may be parcelled out anddone individually, some must be done interactively, with group members providing one anotherwith feedback, challenging reasoning and conclusions, and perhaps most importantly, teachingand encouraging one another. 4. Appropriate use of collaborative skills. Students are encouraged and helped to develop andpractice trust-building, leadership, decision-making, communication, and conflict managementskills.

5. Group processing. Team members set group goals, periodically assess what they are doing wellas a team, and identify changes they will make to function more effectively in the future.

\section{Why Cooperative Learning}

Many people have different opinion about the reason to use coopertive learning in their teaching. According to Felderand Brent (2007) there are several 
reasons why cooperative learning works as well as it does. The idea that students learn more by doing something active than by simply watching and listening has long been known to both cognitive psychologists and effective teachers and cooperative learning is by its nature an active method. Beyond that, cooperation enhances learning in several ways. Weak students working individually are likely to give up when they get stuck; working cooperatively, they keep going. Strong students faced with the task of explaining and clarifying material to weaker students often find gaps in their own understanding and fill them in. Students working alone may tend to delay completing assignments or skip them altogether, but when they know that others are counting on them, they are motivated to do the workin a timely manner.

Moreover, they also explain about the benefit of cooperative learning. They state that The proven benefits of cooperative learning notwithstanding, instructors who attempt it frequentlyencounter resistance and sometimes open hostility from the students. Bright students complain aboutbegin held back by their slower teammates; weak or unassertive students complain about beingdiscounted or ignored in group sessions.

\section{Small Group Discussion and Value of Small Group}

Surgenor (2010) explore about the value of using small group in teaching. He says that the lecture falls short when it comes to some of the generic and transferable skills required for employers, professional bodies, and in keeping with University strategic plans, e.g.,

1. Analytic skills, Communication Skills, presentation skills (Griffiths, Partington)

2. Competence in personal and interpersonal skills and being able to work with people is a key requisite to success in management' (Foreman \& Johnson, (2001)

3. Interpersonal, self-management, analytical (UCD Strategic Plan, Priority 3)

Moreover, according to Ruddok , Luker, Griffiths, Houston \& Lazenbatt cited by Surgenor (2010) stated that students enjoyed and benefited from small groups. The tutorial specifically has been noted for its value in

1. Complementing knowledge in lectures.

2. Expanding on the concepts considered in lectures.

3. Encouraging student reflection

4. Developing students' communication skills

5. Encouraging active life-long learning

\section{Small Group Work}

Using small groups in classroom activities is an effective wayto teach both writing and language skills.Small group workprovides an opportunity for learners 
to focus on learning a lan-guage as well as learning how to write.Small group work alsohelps emphasize learning to communicate through interactionwith others (Nunan, 1991).

Small group work also leads to effective writing instruction.Strong (1990) found that by focusing their attention on eachother's writing in small groups, students wrote more elaborateanswers. Whether a small group of students generated ideas oreven examined the grammar of each other'scompositions, therewas a significant increase in the amount that they wrote over asfcw as ten hours of instruction.

\section{Small Group Writing Procedures}

Connery and Vohs (2006) explain the following procedure of small group writing procedure: 1) Brainstorming, 2) Informationgathering, 3) Organizing, 4) Drafting 5) Revising, 6) Editing. As your group works, members shouldalternate as much as possible between performing these tasks individually and working with the group, orat least with another group member. The only task that seems almost necessarily solitary is drafting; and, infact, many authors collaborate even at this level, sitting together, talking sentences and writing them downbut this takes great patience and an almost intuitive communication process, both of which many of us lack.

Brainstorm. Having established the general characteristics of the writing problem (audience, purpose, message, andpersona), the group should then begin to brainstorm out the paper by using the problem-solving proceduresoutlined above. Some or all of the contents of the paper may be pre-determined by the assignment, but inmany cases the instructor will leave you a great deal of choice or at least a lot of room to move within theguidelines offered. If necessary, brainstorm for possible topics, evaluate them, and choose one. Thenbrainstorm for possible subtopics, evaluate them, and choose the most effective ones. Share informationthat individual members already possess. You might go so far as to brainstorm and discuss possibleorganizations for the paper.

Information gathering: Groups with the luxury of a large amount of commonly convenient time mightarrange to work in the library simultaneously. Members don't have to be working collaboratively on thepaper chase for information - that would be an inefficient duplication of tasks. However, if one memberhas trouble tracking down an individual bit of information, he can fall back on some of the others for help.And since the information sought after by one member can be of use to another, working at a centrallocation-a library table commandeered from other students - can expedite everybody's work. Plus, it's just good for the group's sense of solidarity to see everybody working. Should the group arrange such acoordination of work, any members who don't show up can expect some hostility from other groupmembers, no matter how much work they have done on their own.

Drafting and revision: The group will probably do well to meet once after individual members havegathered information but before they have started writing. At this meeting, each member should report tothe group the information found-what one member has found may affect what another member writes. The 
group as a whole should evaluate the quality of the information-its reliability, objectivity,applicability, and so on. And the group as a whole can decide if further information is needed.

The group may not need to meet as a whole during the initial drafting and revision processes, but youshould continue to work collaboratively-perhaps on a buddy system. If possible, you might create aconvenient centra1 location for group members to drop off copies of their sections as they finish. Computerbulletin boards or file servers are particularly useful for this purpose. Having all of the different pieces ofthe final paper on compatible diskettes will also make the final assembly of the paper a lot easier.

Each section that gets drafted should be read by at least one pre-assigned member other than the author, andthis "reviewer" should offer the author comments primarily about the substance of the section. Whatquestions remain unanswered? What assertions are insufficiently supported? What connections are unclear? What material seems irrelevant? In order to do a good job, the reviewer should try to imagine himself orherself as the intended audience for the pieceboth the instructor/TA audience and the pretended outsideaudience. What would these people be looking for in the piece? Would they find it? The reviewer shouldtalk with the author about the piece thus far, both its assets and its liabilities - and should also write downfor the author at least four or five suggestions for substantial improvements. Limit your suggestions tocomments about substance at this point — no comments about surface features like spelling, punctuation, usage or grammar are necessary at this early stage.

After all the writers have revised their sections at least once, they should distribute copies to all members ofthe group, a day or two before the next meeting, so that everybody can read everything before the meeting. At the meeting, the group should discuss the work in progress, section-by-section, offering finalsuggestions to each writer about the second-to-last revision. After the section-by-section work, the groupshould consider what the piece as a whole looks like. Has the organization remained firm and logical? Areconnections clear? Fill in any gaps that may have been created as the paper expanded and developed.

If everyone has done a good job, you will find yourself with more than enough material. Think long andhard about what material can be cut. Remember that none of the material has any merit in and of itself.Material is only important insofar as it contributes to your purpose and message. In order to alleviate anyhard feelings by the author, phrase all suggestions about cuts in terms of the material's contribution to thepurpose, and be sure to let the author know that you appreciate the work that went into researching andwriting the material.

Again, individual authors should work solitarily, making the final substantial revisions to their sections ofthe body of the paper, as suggested by the group. Subsequently, they should do one revision for style, usage, and grammar: check topic sentences, transitions, paragraph coherence and continuity, ambiguouspronouns. Finally, after revising, each author should do one reading for editing: spelling, punctuation,subject-verb agreement, pronoun-agreement.

Editing: After this laborious process, members should again trade off with at least one other member whoshould do at least one revision and one reading 
dedicated to correcting surface details like grammar, usage,spelling, and punctuation. As you edit your colleagues' work, make your corrections freely. Cutunnecessary words, correct usage and spelling errors, and clear up any ambiguities.

Once again, a group meeting is in order once each section is in its almostfinal form. Each group membershould have read every section thoroughly at this stage. This is the time for any fears, hopes, or qualmsabout the paper to be expressed before it is too late. After any final discussion and decisions, finalassignments should be made. It may be necessary to write a short introduction-assign two people (writerand reviewer/editor) to do it. It may be necessary to consolidate all documentation onto a single page ofreferencesassign two people (compiler and editor). Finally, of course, it will be necessary to prepare thefinal copy of the document. If all the sections are on compatible diskettes, this is hardly a problem at all. Ifthe paper needs re-typing, however, the easiest solution is to all chip in a few dollars and hire a typist. Eachmember should be assigned to several pages (preferably not their own) to make sure that the copy that'sgoing to go to the typist is accurate and legible.

Finally, the group should meet one more time, preferably some place where something tasty is servedinexpensively.Once again, a group meeting is in order once each section is in its almost-final form. Each group membershould have read every section thoroughly at this stage. This is the time for any fears, hopes, or qualmsabout the paper to be expressed before it is too late. After any final discussion and decisions, finalassignments should be made. It may be necessary to write a short introduction-assign two people (writer

and reviewer/editor) to do it. It may be necessary to consolidate all documentation onto a single page ofreferences - assign two people (compiler and editor). Finally, of course, it will be necessary to prepare thefinal copy of the document. If all the sections are on compatible diskettes, this is hardly a problem at all. Ifthe paper needs re-typing, however, the easiest solution is to all chip in a few dollars and hire a typist. Eachmember should be assigned to several pages (preferably not their own) to make sure that the copy that'sgoing to go to the typist is accurate and legible.

Finally, the students can collect their writing to the teacher even they can post their writing product on wall magazine.

\section{Conclusion}

From the previous explanation, it can be concluded that

1. Different aspects of language between Bahasa Indonesia and English as the target language influence the learners to master English skills like writing.

2. Students' writing ability can be successful if the students are involved in appropriate way in order to improve their writing.

3. Students are from different background of English competencies sholud be put in a small group of writing activities, because they can help one another 
4. Small group can promote not only students' writing achievement but also other aspects like increasing their cooperation, self confident, and social values.

\section{References}

Connery, Brian. A. And Vohs, John. L. 2006. Group Work and Collaborative Writing. University of California

Diaz-Rico, Lynne T. 2008. Strategies for Teaching Learners. Pearson Educations, Inc.

Felder, Richard. M and Brent, Rebecca. 2007. Cooperative Learning. Department of Chemical Engineering, N. C. State University

Heinich, Robert et all. Instructional Media and Technologies for Learning.

Johnson, D. W. And Johnson, R.T. 1991. Learning together and alone: cooperative, competitive, and individualistic learning. Massachusets.

Larsen, Diane and Freeman. 2000. Teaching and Principles in Language Teaching. Oxford University Press.

Nunan, D. 1991. Communicative Tasks and The Language Curriculum. TESOL Quarterly, 25.

O'Malley and Pierce. 1996. Authentic Assessment for English Language Learners. Addison Wesley Publishing Company.

Surgenor, Paul. 2010. Large and Small Group Teaching. UCD Dublin Teaching and Learning/ Resources.

Strong, G. 1990. A Comparison Group Study on the Effects of Instruction in Writing Heuristics on the Expository Writing of ESL Students. University of British Columbia. 